\title{
Helminthiasis among Elderly with Long Term Care Setting, Sisaket Province, Thailand
}

\author{
Norasan, S., ${ }^{1,2}$ Hassan, R. ${ }^{2,3}$ and Nithikathkul, C. ${ }^{1,2^{*}}$ \\ ${ }^{1}$ Program in Health Science, Faculty of Medicine, Mahasarakham University, Thailand \\ ${ }^{2}$ Tropical and Parasitic Diseases Research Unit, Faculty of Medicine, Mahasarakham University, 44000, \\ Thailand, E-mail: nithikethkul2016@gmail.com \\ ${ }^{3}$ School of Medicine, University of Sain Malaysia, Malaysia \\ *Corresponding Author
}

DOI: https://doi.org/10.52939/ijg.v17i5.2031

\begin{abstract}
Beyond the COVID-19 pandemics, from the Era of New normal along with advancement in technology is a concurrent advancement in public health. Prevention and control programs dealing with tropical and parasitic diseases have been developed and implemented. However, even with these advances, tropical and parasitic diseases remain a serious concern for the public health system in Thailand. The first cross-sectional analytical study identified risk factors associated with helminthiasis among the elderly in Srisaket Province. The investigators already visited and collected from 293 subjects during Year 2020. The data were analyzed descriptive statistics include number, percentage, mean, standard deviation, minimum, and maximum values. Inferential statistics investigated the association of factors affecting the prevention behavior of helminthiasis infection among the elderly by Pearson's correlation coefficient statistics. Analysis equation was also used to predict the relationship between two groups of variables by using Stepwise Multinomial logistic regression statistics. The study revealed a higher prevalence of helminthiasis in the population age group of over 60 to 90 years old compared to other age groups. It also indicated that males (37.9\%) were more significant than females $(62.1 \%)$. The results of fecal eggs or larvae counts of elderly in the overview showed that they were hookworm infection $6.80 \%$, Taenia infection $4.40 \%$ and Opisthorchis's $2.40 \%$ respectively. The results revealed 4 factors associated with preventive behavior of helminthiasis knowledge, perceived benefit, social support, and self-efficacy respectively. The stepwise multiple regression analysis used to predict the preventive behavior of helminthiasis among elderly in Sisaket Province could jointly explain 16.20\% of the variance $\left(R^{2}=0.162, R_{a d j}^{2}=0.150, S E_{\text {est }}=7.39094, F=13.383, p=0.03\right)$ of preventive behavior of helminthiasis among elderly with significant at level 0.05. Therefore, establishing the long-term care preventive model of helminthiasis should focus on these factors.
\end{abstract}

\section{Introduction}

Over the last 5 decades, Thailand's population structure was changing rapidly, with the ageing population (age 60 and older) that increasing from 1.21 million people in 1960 to 10 million in 2014, or about $15 \%$ of the total (Office of Policy and Strategy, Office of the Permanent Secretary, Ministry of Public Health, 2017). The estimated population of Thailand in 2010-2040 showed that the proportion of the elderly population would continue increasing from $13.2 \%$ in 2010 to $32.1 \%$ in 2040. Meanwhile, the proportion of the child population (under 15 years old) and work-force population (aged 15-59 years) was decreasing. The estimate of Thailand also shows that in the next 30 years, the overall population growth rate will decrease, starting negatively during 2025-2030, onwards from $-0.1 \%$ per year to $-0.5 \%$ per year during 2035-2040. Meanwhile, the increase rate of the ageing population is projected to increase at a rate of $4.2 \%$ in the year $2010-2015$ to $3.0 \%$, in 2025-2030 drop to $1.2 \%$, in 2025-2530, the increase rate of ageing is still higher than the increasing rate of the total population (Division of Health Promotion, Department of Health, Ministry of Public Health, 2012), that shown in Figures 1, 2, 3. In the rural community of Chachoengsao Province. The overall soil-transmitted helminth infections $14.3 \%$, high prevalence in male participants over 40 years who raise dogs in the households and did not wear boots while working in fields. The focus on intervention is required by improving sanitation and personal hygiene to prevent the spread of intestinal parasitic infections. (Suntaravitun and Dokmaikaw, 2018). Highest infections were found in 41-50 aged range. (Phuttharak and Siriphaporn, 2014). 


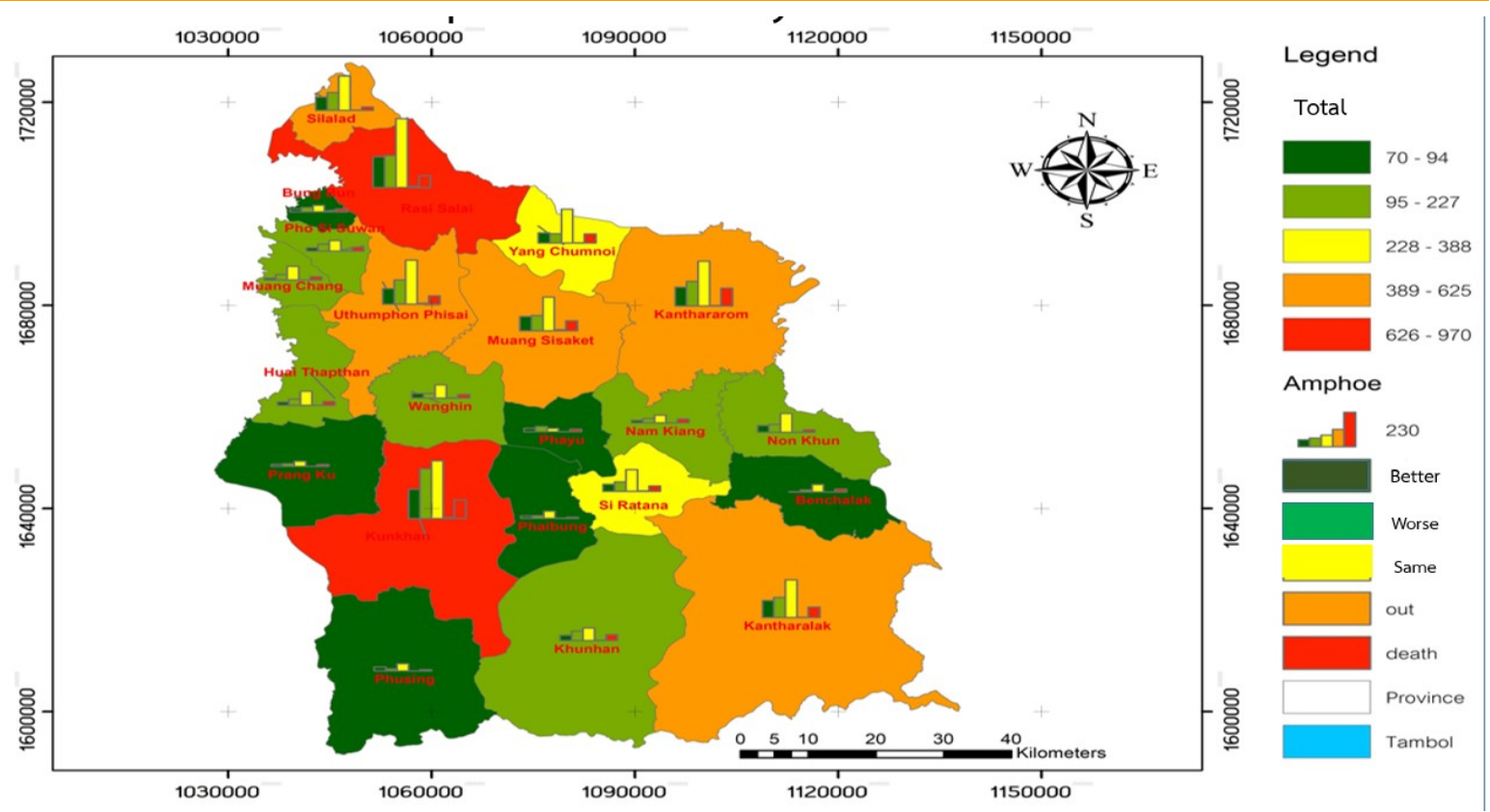

Figure 1: The dependent elderly information divided by districts in Sisaket Province

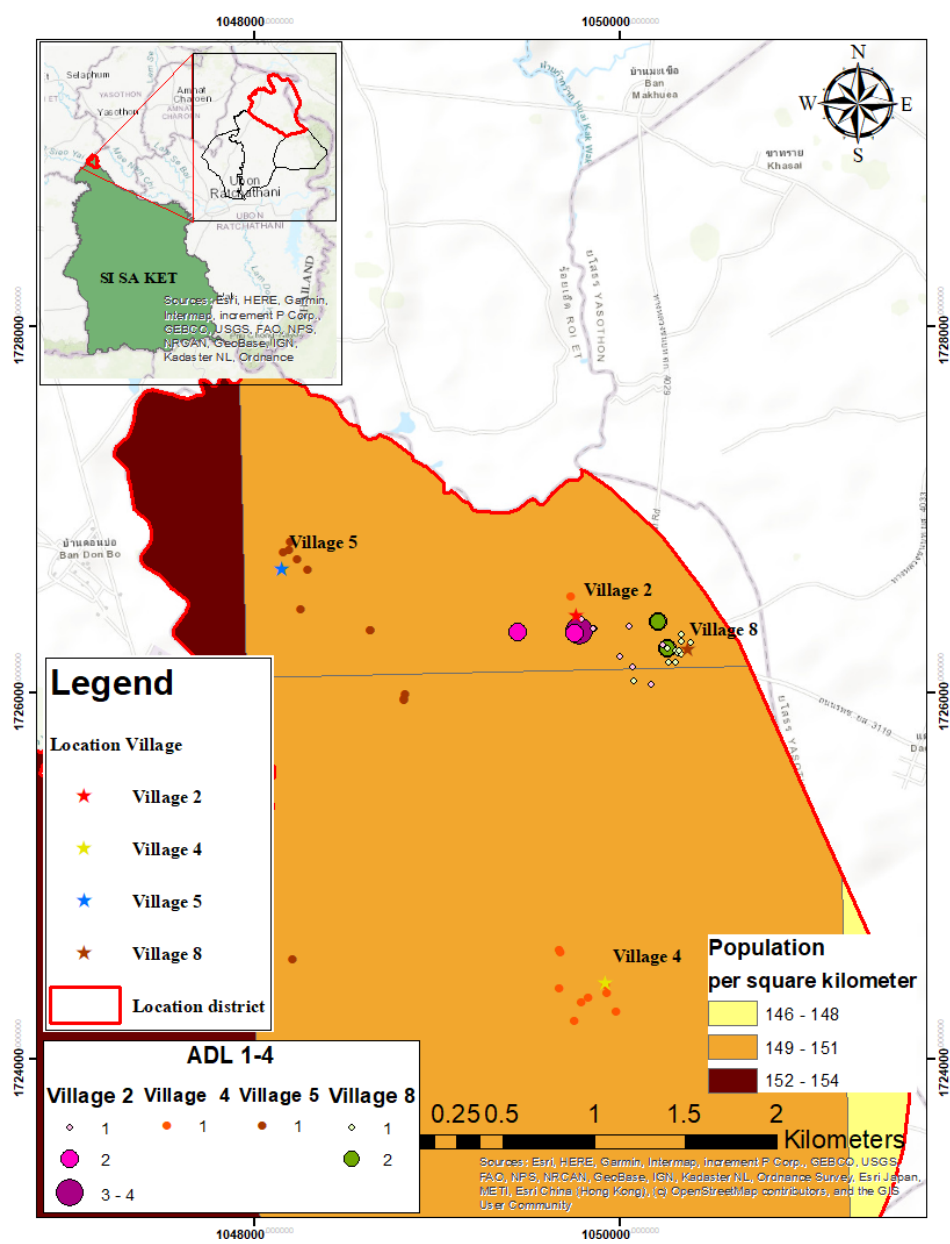

Figure 2: The ADL of dependent elderly information in Khlikling sub-district, Silalad district, Sisaket Province 
As the researchers were the primary care staff unit and played role in caring for people in all age groups, especially the elderly population showed increasing the level of dependency by $2.70 \%$ (Silalad District Public Health Office Annual Report, 2016). Most of the causes of occurrence of parasitic infection are due to complications from chronic diseases, pathology, deteriorating body conditions, and various disabilities that affect the ability to help themselves in daily life (Sirikampeng and Phosing, 2017). The prevalence of intestinal parasitic infections in elderly people living in the urban areas of Aiquara, Bahia, was high, however, there was no association between intestinal parasites and sociodemographic characteristics, lifestyle, or health ( $\mathrm{p}>0.05)$ (Ahmadiara and Hajimohammadi, 2017). Study on intestinal parasitosis among the elderly people in Kathmandu Valley, Nepal government elderly homes showed a significantly high parasitic prevalence $(50.8 \%)$ followed by the rural community $(46.8 \%)$ and private elderly homes 21.2 (Bikash et al., 2006). A few reported in the elderly group, where screening is relatively rare and has been defined as a tropical disease. The operation showed the disease control not being exhausted and likely affected the quality of people's life as a whole such as gastrointestinal diseases, and sometimes severe death. Nowadays, The incidence of helminthiasis in elderly is increasing and caused health deterioration, hence immediate investigation is required to reduce the infection and complications resulted by these infections Therefore, prevalence of helminth infections among the elderly, as well as establish the prevention, control, and provide longterm care in the elderly group to be effective and have a good quality of life.

\section{Methodology}

The cross-sectional analytical study identified risk factors associated with helminthiasis among the elderly in Sisaket Province. The investigators already visited and collected from 293 subjects during Year 2020. The samples were using the sample size calculation formula and Accuracy Parameter Estimated (AIPE), which Kelly and Maxwell (2003) presented with the formula for calculation as follows:

$$
N_{M}=\left(\frac{Z_{(1-\alpha) / 2}}{w}\right)\left(\frac{1-R^{2}}{1-R_{X X j}^{2}}\right)\left(\frac{\chi_{(1-\gamma ; N-1)}^{2}}{N-p-1}\right)+p+1
$$

Where:

Equation 1

$$
\mathrm{N}_{\mathrm{M}}=\text { Number of samples }
$$

$\mathrm{N}=50 \%$ of the chance to get $95 \% \mathrm{CI}$ of $\mathrm{R} 2$ less than 0.01

$\mathrm{P}=$ Number of predictive variables in the full model (assigned to 5 predictors)

$\mathrm{A}=$ Decision point level for confidence range test (0.05)

$\mathrm{w}=$ Half of the confidence range of the main predictive variable

$\mathrm{R}^{2}=$ Squared of the coefficient of regression analysis for the full model, which is based on the expectations and estimates of a study of Saengprachat (2010) factors correlated with the people's prevention behaviour of liver cancer and bile duct cancer, Ubon Ratchathani Province $\left(\mathrm{R}^{2}=0.520\right)$

$\mathrm{R}_{\mathrm{x}-\mathrm{xj}}=$ Squared of regression coefficient of the main independent variable with independent Variable $(\mathrm{R} 2=0.230)$ ( Saengprachat, 2010)

$\mathbf{X}^{2}{ }_{(1-\gamma ; N-1)}(=$ Quartile of Chi-Squaw Distribution (0.8)

The sample size was calculated in the AIPE function of THE STATA version 8.2, getting the sample size for the risk of helminth infection in the elderly 130 subjects, Sisaket Province. The investigators determined the probability of design effect twice with samples of 260 subjects replacement for 293 losses subjects. A questionnaire of factors influencing affecting the prevention behavior for helminthiasis was investigated among the elderly in Sisaket Province. All subjects were interviewed and stool specimens were collected. Stool specimens were carefully stored before examination in the study areas. The Modified Kato Katz technique was performed to quantify the intensity from samples (Saengprachat, 2010). The presence of helminthiasis parasite eggs was determined microscopically.

The questionnaire was created through the application as follows: content validity was used by 3 experts to verify the content's accuracy by reviewing the accuracy of content along with language and idioms used. Afterwards, revisions were done according to suggestions before further testing the reliability of the questionnaire and finding consistency between the purpose and the content by finding (Index of Item Objective Congruence: IOC). Results found that the IOC was between $0.67-1.00$ and the reliability test by taking a verified and revised questionnaire to experiment with samples that are similar to the target of 30 sets in Yasothon Province. Lastly, result was analyzed for reliability on knowledge factor of helminthiasis $=0.86$, attitude factor about helminthiasis $=0.82$, social norm factor $=0.84$, social support factor $=$ 0.86 , according to awareness on health belief factor $=0.88$, respectively. The data analysis were 
descriptive statistics to analyze the basic data of samples by using frequency distribution, percentage, average, standard deviation using normal distribution or median, 25th percentile, 75th percentile. When using other distributions, Inferential Statistics is tested to find variable relationships with behavior using stepwise multilinear regression analysis. The analysis. The study has been approved by the Human Research Committee in the University of Mahasarakham. University ICH-GCP Ref. No. 154/2020 Approved 20 May 2020 based on the declaration of Helsinki
(Declaration of Helsinki) and good clinical research practices.

\section{Results}

The result of elderly in Sisaket Province showed $62.1 \%, 41.6 \%$ and $90.4 \%$ were female, age group 60-64 and primary school level of education respectively. From the crucial illness history hypertension, hypertension with diabetes and other chronic diseases were $22.5 \%, 8.5 \%$ and $7.2 \%$ respectively (Table 1$)$.

Table 1: Demographic information of elderly in Sisaket Province

\begin{tabular}{|c|c|c|c|}
\hline Information & & Number & Percentage \\
\hline \multicolumn{4}{|l|}{ Sex } \\
\hline & Male & 111 & 37.9 \\
\hline & Female & 182 & 62.1 \\
\hline \multicolumn{4}{|l|}{ Age (Year) } \\
\hline & $60-64$ & 122 & 41.6 \\
\hline & $65-69$ & 83 & 28.3 \\
\hline & $70-74$ & 50 & 17.1 \\
\hline & $75-79$ & 36 & 12.3 \\
\hline & $>80$ & 2 & 7 \\
\hline & \multicolumn{3}{|c|}{ Mean (S.D.) : Median $\left(\mathrm{P}_{25}: \mathrm{P}_{75}\right) 67(5.18): 66.00(63,72)$} \\
\hline \multicolumn{4}{|c|}{ ( ) } \\
\hline & Illiterate & 17 & 5.8 \\
\hline & Primary school & 265 & 90.4 \\
\hline & Over primary school & 11 & 3.8 \\
\hline \multicolumn{4}{|l|}{ Occupation } \\
\hline & Agriculture & 272 & 92.8 \\
\hline & Employee & 5 & 1.7 \\
\hline & Business & 2 & 0.7 \\
\hline & Etc & 14 & 4.7 \\
\hline \multicolumn{4}{|c|}{ Income per month } \\
\hline & $<3000$ baht & 207 & 70.6 \\
\hline & $>3000$ baht & 86 & 29.4 \\
\hline \multicolumn{4}{|c|}{ Mean (S.D.): Median (P25: P75), 3,718.80 (4,363.94): 2,350 (1,500 : 4,000) } \\
\hline \multicolumn{4}{|c|}{ Illness history } \\
\hline & DM & 16 & 5.5 \\
\hline & HT & 66 & 22.5 \\
\hline & $\mathrm{HT}+\mathrm{DM}$ & 25 & 8.5 \\
\hline & Chronic diseases & 21 & 7.2 \\
\hline & None & 165 & 56.3 \\
\hline \multicolumn{4}{|l|}{ BMI } \\
\hline & Normal & 147 & 50.2 \\
\hline & Quite Fat & 99 & 33.8 \\
\hline & Thin & 24 & 8.2 \\
\hline & Overweight & 23 & 7.8 \\
\hline \multicolumn{4}{|c|}{ Care giver duration } \\
\hline & $<3$ Years & 106 & 36.1 \\
\hline & $>3$ Years & 187 & 63.8 \\
\hline & \multicolumn{3}{|c|}{ Mean (S.D.): Median (P25: P75), 1.97 (0.68): $3(2: 3)$} \\
\hline \multicolumn{4}{|c|}{ Self-care management } \\
\hline & Very good level & 3 & 1 \\
\hline & Partial help by child & 241 & 82.3 \\
\hline & Partial help by care giver & 34 & 11.6 \\
\hline & Fully help by relatives & 13 & 4.4 \\
\hline & Fully help & 2 & 0.7 \\
\hline \multicolumn{4}{|c|}{ Community support } \\
\hline & Occupation & 9 & 3 \\
\hline & Income & 10 & 3.4 \\
\hline & Health & 178 & 60.6 \\
\hline & Social & 96 & 32.8 \\
\hline \multicolumn{4}{|c|}{ Organization support } \\
\hline & PCU & 112 & 38.2 \\
\hline & Sub district administrative organization & 23 & 7.8 \\
\hline & Community & 11 & 3.8 \\
\hline & Another organization & 145 & 49.5 \\
\hline & none & 1 & 0.3 \\
\hline \multicolumn{4}{|l|}{ Defecation } \\
\hline & Flush toilet & 277 & 94.5 \\
\hline & Defecate to water reservoirs & 8 & 2.7 \\
\hline & Defecate to forest & 3 & 1 \\
\hline
\end{tabular}




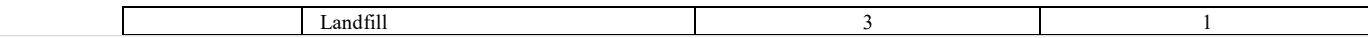

250

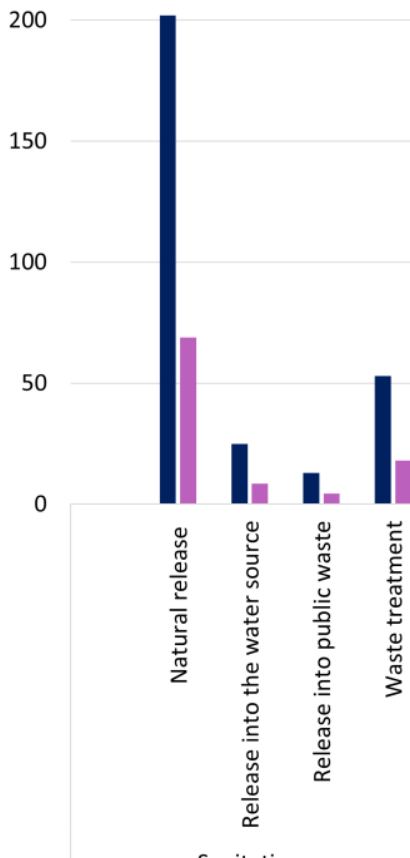

Sanitation

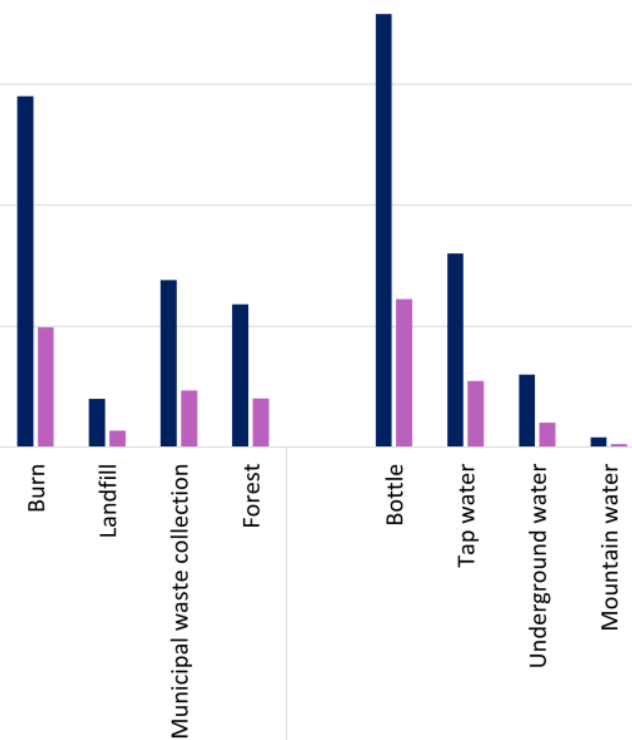

House waste disposal

Drinking water supplied

n Number $\quad$ Percentage

Figure 3: Environmental information risk for helminthiasis of dependent elderly in Sisaket Province

Finding the health status and health care of BMI, care giver duration and self-care management showed normal $50.2 \%$, more than 3 years $63.8 \%$ and partial help by a child $82.3 \%$ approximately (Tables 1, 2). The parasitic infection such as hookworm, Taenia and Opisthorchis riverine were $6.8 \%, 4.4 \%$ and $2.4 \%$ respectively $\%$ (Figure 4 ).

The environmental risk factor associated with the helminthiasis of dependent elderly in Sisaket Shown in Figure 3. The majority of the elderly showed natural release of sanitation, none used fertilizer, and drinking water with bottles. The Figure 4 showed the majority elderly usually examined for parasitic infection with PCU. None was treated and none had parasitic examination. Majority of elderly used the flush toilet, reared chicken and burnt the house waste disposal (Figure 5).

The results showed level analysis of factors affecting preventive behavior for the helminthiasis of the dependent elderly in Sisaket Province. Knowledge factors levels of prevention behavior for helminthiasis was high level. The mean was 14.83 (1.55) possible score range 14.64-15.00 points compared to $91.50-93.75$ percent. Attitudes of prevention behavior for helminthiasis in the middle level, the mean value was 50.74 (S.D. $=6.09$ ), possible score range of 50.03-51.43, compared to 55.59-57.14 percent. Social norms of prevention behavior for helminthiasis was high level, an average value equal to 38.91(4.32) possible scoring range 38.41-39.41 points by percentage 85.3687.58. Social support on helminthiasis prevention behaviors of the elderly the middle average 47.87 (6.33) possible score range 47.14-48.59. The comparison was $78.56-80.98$ percent.

Perception of Diseases severity of the dependent elderly helminthiasis prevention behavior in the middle the average value was 18.75 (3.60), possible score range 18.33-19.16 compared to 67.89-70.96 percent. Perception of benefits factors of helminthiasis prevention is high; the average value was 23.37 (2.85). The score range was 23.03-23.69, compared to $85.29-87.74 \%$. Recognition of barriers factors of the elderly helminthiasis prevention behavior in the middle level, the mean value was 22.39 (3.73), possible score range 21.97-22.81. With a percentage of 73.03-76.03. Self-defense ability factors of prevention behavior for helminthiasis was high average value is 38.70 (3.86). 


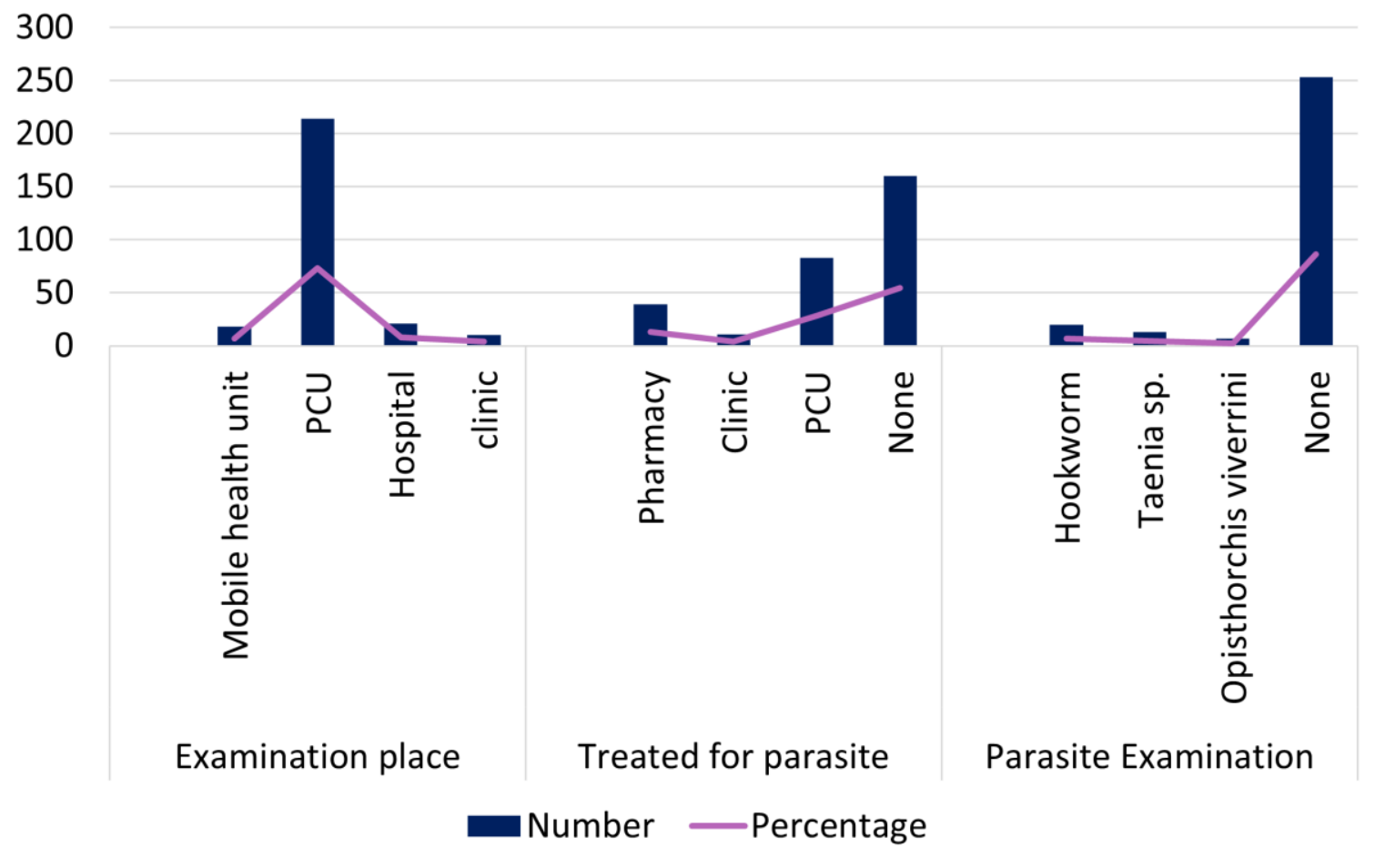

Figure 4:Helminthiasis information of dependent elderly in Sisaket Province

\section{0 \\ 120 \\ 100 \\ 80 \\ 60 \\ 40 \\ 20}

0

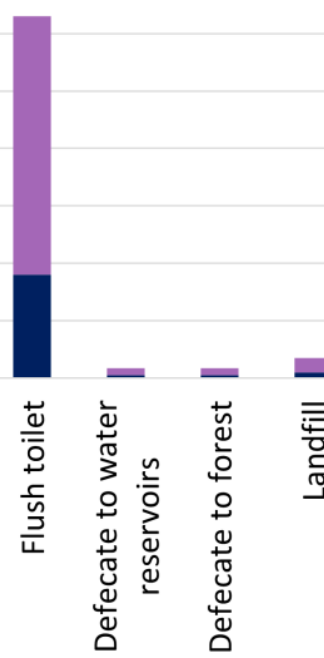

Defecation

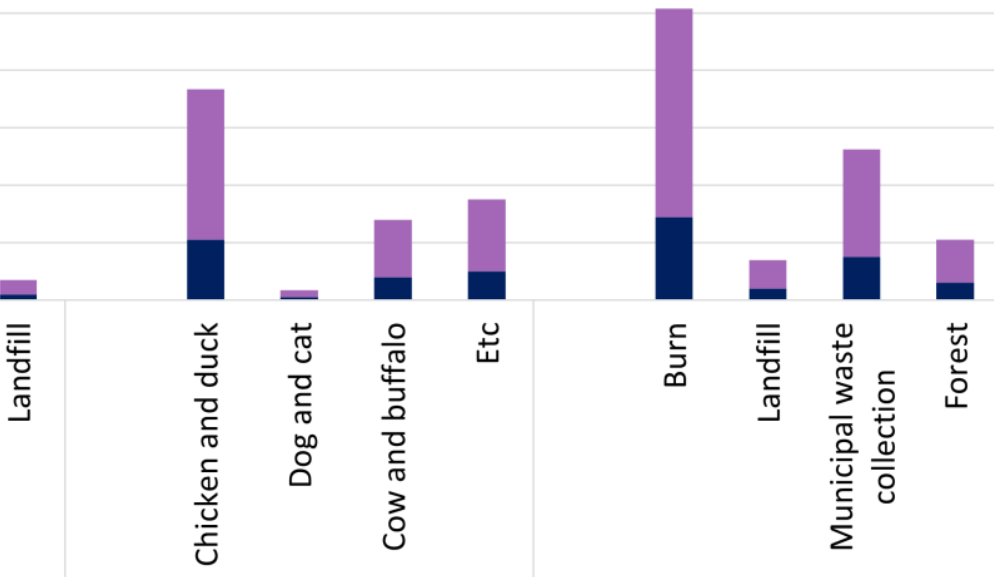

House waste disposal

Domestication of animals

Number Percentage

Figure 5: Environmental information risks for helminthiasis of dependent elderly in Sisaket Province

The score range is 38.26-39.13, compared to 91.0993.16 percent. The environmental factors of prevention behavior for helminthiasis still high level. The average value was 19.98 (1.25) possible score range 19.83-20.12, compared to 94.42$95.80 \%$,and the dependent elderly helminthiasis prevention behavior. in the middle the average value was 56.02 (8.02), possible score range 55.11-56.94 points, compared to $68.03-70.29$ percent, according to the detailed order in Table 2. The risk factors that correlated with prevention behaviors for helminthiasis of the dependent elderly in Sisaket 
Province. These factors showed variables that had preliminary correlation with prevention in the infection of helminthiasis in the dependent elderly. There were two variables in Sisaket Province: knowledge of helminthiasis $(r=0.308$, p-value $<0.001)$ and factor of Perception of benefits $(r=$ $0.203 \mathrm{p}$-value $<0.001$ ), Sequence, attitude factor $(r=$ $0.020, \mathrm{p}$-value $=0.732)$, Social norms factor $(\mathrm{r}=$ 0.034 , p-value $=0.563)$, Social support $(r=0.106$, P-value $=0.069)$, Perception of Diseases severity factor $(r=0.024$, P-value $=0.686)$ Perception of benefits factor, Recognition of barriers factor $(\mathrm{r}=$ 0.030 , P-value $=0.607$ ), Self-Defense ability factors $(\mathrm{r}=0.41$, P-value $=0.484)$ and prophylactic environmental factors $(\mathrm{r}=0.066$, P-value $=0.260)$. There was not enough data to establish a correlation with prevention in the infection of helminthiasis in the dependent elderly in Sisaket Province. Details are in Table 3.The factors that related prevention behavior for helminthiasis of dependent elderly in Sisaket Province found that knowledge factor was the first associated predictor variable of factor significantly at level .05 which can explain with a variation of factor associated with the behavior in helminthiasis prevention behavior of dependent elderly in Sisaket Province by $9.5 \%\left(\mathrm{R}^{2}=0.095\right)$. Also, predictor variables were perceived with benefits factor were with a coefficient prediction with a significant increase at level .05 that could jointly explain the variety of factors that are associated with the prevention behavior for helminthiasis of dependent elderly in Sisaket Province by $4 \%\left(\mathrm{R}^{2}=0.040\right)$. After adding one more predictor variable which was the social support factor, it showed that the coefficient of prediction was significantly increasing at level .05 that could jointly explain with a variation of prevention behavior in helminthiasis of the dependent elderly in Sisaket Province by $1.3 \% \quad\left(\mathrm{R}^{2}=0.013\right)$. Lastly, adding the predictor variable of self-efficacy showed a coefficient of prediction increasing significantly at level .05 and can explain with a variation of prevention behavior for helminthiasis of dependent elderly in Sisaket Province 1.4 $\left(\mathrm{R}^{2}=0.014\right)$.

Table 2: The level of factors affecting prevention behavior for the helminthiasis of the dependent elderly. Sisaket Province $(n=293)$

\begin{tabular}{|l|c|c|c|c|}
\hline \multicolumn{1}{|c|}{ Helminthiasis prevention behaviors } & Range & Mean (S.D) & $\mathbf{9 5 \%}$ CI & Score level (\%) \\
\hline Knowledge & $0-16$ & $14.83(1.55)$ & $14.64-15.00$ & $91.50-93.75$ \\
\hline Attitude & $16-90$ & $50.74(6.09)$ & $50.03-51.43$ & $55.59-57.14$ \\
\hline Social norms & $9-45$ & $38.91(4.32)$ & $38.41-39.41$ & $85.36-87.58$ \\
\hline Social support & $20-60$ & $47.87(6.33)$ & $47.14-48.59$ & $78.56-80.98$ \\
\hline Perception of Diseases severity & $9-27$ & $18.75(3.60)$ & $18.33-19.16$ & $67.89-70.96$ \\
\hline Perception of benefits & $9-27$ & $23.37(2.85)$ & $23.03-23.69$ & $85.29-87.74$ \\
\hline Recognition of barriers & $10-30$ & $22.39(3.73)$ & $21.97-22.81$ & $73.03-76.03$ \\
\hline Self-defense ability & $14-42$ & $38.70(3.86)$ & $38.26-39.13$ & $91.09-93.16$ \\
\hline Environment condition & $7-21$ & $19.98(1.25)$ & $19.83-20.12$ & $94.42-95.80$ \\
\hline Behaviors & $27-81$ & $56.02(8.02)$ & $55.11-56.94$ & $68.03-70.29$ \\
\hline
\end{tabular}

Table 3: The correlation of factors associated with anti-helminthic behavior in the dependent elderly. $(\mathrm{n}=293$ people $)$

\begin{tabular}{|l|c|c|c|}
\hline \multicolumn{1}{|c|}{ Factors } & Mean (S.D.) & Correlation level & p-value \\
\hline Knowledge & $14.83(1.55)$ & 0.308 & $<0.001^{* *}$ \\
\hline Attitude & $50.74(6.09)$ & 0.02 & 0.732 \\
\hline Social norms & $38.91(4.32)$ & 0.034 & 0.563 \\
\hline Social support & $47.87(6.33)$ & 0.106 & 0.069 \\
\hline Perception of Diseases severity & $18.75(3.60)$ & 0.024 & 0.686 \\
\hline Perception of benefits & $23.37(2.85)$ & 0.203 & $<0.001^{* *}$ \\
\hline Recognition of barriers & $22.39(3.73)$ & 0.03 & 0.607 \\
\hline Self-defense ability & $38.70(3.86)$ & 0.041 & 0.484 \\
\hline Environment condition & $19.98(1.25)$ & 0.066 & 0.26 \\
\hline
\end{tabular}


In summary, there were 4 good predictor variables attributed to prevention behavior for helminthiasis of the dependent elderly in Sisaket province knowledge, perceived benefits, social support and self-efficacy factors could jointly explain with a variation of prevention behavior for helminthiasis of the dependent elderly in Sisaket province by $16.20 \%$ $\left(\mathrm{R}^{2}=0.162, \mathrm{R}_{\text {adj }}^{2}=0.150, \mathrm{SE}_{\text {est }}=7.39094, \mathrm{~F}=13.383\right.$, $\mathrm{p}=0.03$ ) respectively. Details are shown in Table 4 .

Multiple-linear regression analysis found that the variables which were able to co-describe the variability of factors associated with the disease prevention behaviors of the elderly were $16.20 \%\left(\mathrm{R}^{2}\right.$ $=0.162, \mathrm{R}^{2} \mathrm{adj}=0.150$, SEest $=7.39094, \mathrm{~F}=$ 13.383, $\mathrm{p}=0.03)$.

1. Knowledge factor is a factor that correlates with the prevention behavior for helminthiasis of the dependent elderly Sisaket Province is the most powerful, with 58.64 percent of the power of the best model $\left(\mathrm{R}^{2}=0.095, \mathrm{R}^{2} \mathrm{adj}=0.092, \mathrm{R}^{2}\right.$ change $=$ $0.095 ; \mathrm{B}=1.681 \beta=0.325$, $\mathrm{p}$-value $<0.001$ ).

2. The perceived factor was a factor that correlated with the prevention behavior for helminthiasis of the dependent elderly Sisaket Province, in the following order, had 24.69 percent of the best model's lead power $\left(\mathrm{R}^{2}=0.135, \mathrm{R}^{2} \mathrm{adj}=0.129, \mathrm{R}^{2}\right.$ change $=$ $0.040 ; \mathrm{B}=-0.595, \beta=-0.212$. , $\mathrm{p}$-value $<0.001$ ).

3. Social support factor is a factor that correlates with the prevention behavior for helminthiasis of the dependent elderly Sisaket Province, next, had 8.02 percent of the best model's lead power $\left(\mathrm{R}^{2}=0.148\right.$,
$\mathrm{R}^{2}$ adj $=0.139, \mathrm{R}^{2}$ change $=0.013 ; \mathrm{B}=0.159, \beta=$ $0.126, \mathrm{p}$-value $=0.022$ ).

4. Self-efficacy factor is a factor correlated with the elderly person's helminthiasis prevention behavior. Sisaket Province, in the following order, had 8.64 percent of the best model's lead power $\left(\mathrm{R}^{2}=0.162\right.$, $\mathrm{R}^{2} \mathrm{adj}=0.150, \mathrm{R}^{2}$ change $=0.014 ; \mathrm{B}=-0.254, \beta=$ 0.121 , p-value $=0.030$ ).

From the analysis, it was found that variable which is a factor correlated with the prevention behavior for helminthiasis of the dependent elderly Sisaket Province. Sort the best variables to predict: knowledge factor, perceived benefit factors, social support factors and self - efficacy factors. The factors of perceiving one's competence according to the sequence of details in Table 5. A stepwise multiple regression analysis to determine the predictive factors of helminthiasis preventive behavior of the elderly in Sisaket Province. The regression model could be written as follows:

The forecasting equation of raw score is:

$\mathrm{Y}^{\prime}$ (prevention behavior in helminthiasis $)=19.419$

$+1.681 \mathrm{X}_{1}$ (Knowledge) $+0.595 \mathrm{X}_{6}$ (Perceived benefits) $+0.159 \mathrm{X}_{4}$ (Social support) $-0.254 \mathrm{X}_{8}$ (Perceived self-efficacy).

The forecasting equation of standard score is:

$\mathrm{Z}_{\mathrm{y}}$ (prevention behavior in helminthiasis $)=0.325$ $Z_{1}$ (Knowledge) $+0.212 Z_{6}$ (Perceived benefits) + $0.126 \mathrm{Z}_{4}$ (Social support) $-0.121 \mathrm{Z}_{8}$ (Perceived selfefficacy).

Table 4: The regression coefficient analyzed the predictive factors associated with prevention behavior in helminthiasis among dependent elderly in Sisaket Province. $(n=293$ subjects $)$

\begin{tabular}{|c|c|c|c|c|c|c|c|}
\hline \multirow[t]{2}{*}{$\begin{array}{l}\text { Model } \\
\text { analyze }\end{array}$} & \multirow[t]{2}{*}{ Variable } & \multicolumn{2}{|c|}{$\begin{array}{l}\text { Regression } \\
\text { coefficient } \\
\text { (Coefficient) }\end{array}$} & \multirow[t]{2}{*}{$\mathbf{R}^{2}$} & \multirow[t]{2}{*}{$\mathbf{R}^{2}$ adj } & \multirow[t]{2}{*}{$\mathrm{Sr}^{2}$} & \multirow[t]{2}{*}{$\begin{array}{c}\mathbf{R}^{2} \\
\text { change }\end{array}$} \\
\hline & & B & $\mathrm{B}$ & & & & \\
\hline \multirow{4}{*}{ The best Model } & Knowledge & 1.681 & 0.325 & 0.095 & 0.092 & 7.64 & 0.095 \\
\hline & Perceived benefit & 0.595 & 0.212 & 0.135 & 0.129 & 7.48 & 0.040 \\
\hline & Social support & 0.159 & 0.126 & 0.148 & 0.139 & 7.43 & 0.013 \\
\hline & Self-efficacy & -0.254 & -0.121 & 0.162 & 0.150 & 7.39 & 0.014 \\
\hline
\end{tabular}

Table 5: The regression coefficient analyzed among Knowledge factors. Perception Benefits factor, Social Support factors and Self-efficacy factors with anthelmintic behavior of the elderly Sisaket Province. $(\mathrm{n}=293$ subjects)

\begin{tabular}{|l|c|c|c|c|}
\hline $\begin{array}{c}\text { prevention behavior in helminthiasis } \\
\text { of the dependent elderly Sisaket Province }\end{array}$ & $\mathbf{b}$ & Beta & t & p-value \\
\hline Knowledge & 1.681 & 0.325 & 5.984 & $<0.001$ \\
\hline Perceived benefit & 0.595 & 0.212 & 3.852 & $<0.001$ \\
\hline Social support & 0.159 & 0.126 & 2.307 & 0.022 \\
\hline Social support & -0.254 & -0.121 & -2.180 & 0.030 \\
\hline \multicolumn{2}{|r}{ Constant $=19.419, \mathrm{R}^{2}=0.162, \mathrm{R}^{2}{ }_{\text {adj }}=0.150, \mathrm{SE}_{\text {est }}=7.39094, \mathrm{~F}=13.383, \mathrm{p}=0.03$} \\
\hline
\end{tabular}




\section{Discussion}

The main outcome of helminthiasis in elderly people is slightly higher in females than male. Similar to the study in Jiangxi province, China, the helminthiasis rates in female population were higher than male (Zeng et al., 2019). In contrast, I study Thammasat hospital, helminthiasis slightly higher in male more than females, $(p<0.05)$. (Puttaruk and Sirisabhabhorn, 2014). The decline of helminthiasis in all age groups, but the decline was less in the higher age group and the prevalence of infection in the elderly population is higher than the lower age group in China (Lin et al., 2015). WHO defined helminthiasis prevalence $>70 \%$ in a population as a high_age group and recommendations included providing anthelmintic treatment to the following atrisk groups: children (1-14 years of age) and women (15-45 years of age). Countries that have made significant impact to effectively control helminthiasis enjoy great commitment from government level decision-makers (WHO, 2017). The Thailand government at all levels played significant roles by prioritizing continuous successful intervention at Sisaket province and the entire country. (Office of Policy and Strategy, Office of the Permanent Secretary, Ministry of Public Health,2017). Helminthiasis is one of the most neglected among the healthcare systems. Its neglect could be a result of its chronic and asymptomatic nature of infection, particularly at an early stage. Helminth infections can, however, cause severe debilitation, morbidity and economic losses among humans and livestock. (Kasl et al., 2018) Therefore, the prevention and control of helminth disease is carried out continuously.

This study found four influencing factors for the prevention of helminthiasis infection among the elderly in Sisaket province and factors affecting the prevention behavior of helminthiasis infection are knowledge, perceived benefits, social support, and self-efficacy.

Knowledge factor influences the preventive behavior of helminthiasis infection among the elderly in Sisaket Province. According to the literature review, it was found out that the ability of an individual to change their behavior is influenced by a variety of factors to support change including education and knowledge to perceived susceptibility, life-threatening diseases, also perceived benefit and barriers. To change behavior, there must be a recorded self-behavior for review and monitoring of daily behaviors, together with induction and motivation. If healthcare behavior has changed properly, it makes an individual healthy, free from any form of sickness and not a burden on society. A similar study also concluded that to develop a village public-health volunteers to have appropriate health behaviors that focus on enhancing awareness of self-ability, risks of health, awareness, training about public-health volunteers' skills continuously make public-health volunteers' awareness self-ability with health behavior and risk of illness. These factors can be combined to predict the health behavior of public-health volunteers in Chanthaburi Province (Wongsaroj et al., 2014). Based on the previous report from Ukkhati and colleagues, it was found out that continuous training for village-health volunteers could urge them to have more appropriate health behavior (Ukkhati et al., 2008).

Perceived benefit factor influences the preventive behavior of helminthiasis among the elderly in Sisaket Province. When a person believes in the risk of a disease and that that disease can result in self-harm, including time waste, discomfort, embarrassment, insecurity, and complications, the person avoids the threat by seeking prevention or treatment. However, the acceptability and willingness to act on anything is caused by the belief that a certain method is a good solution results in good results, useful and most suitable that will not lead to a disease or may result in infection recovery. At the same time, a person needs to believe that cost is a disadvantage or obstacles to prevent. Thus, treatment must be less when compared with the benefits to be gained. The concept was consistent with the previous study consistent with the study of Weeraphon Wisetsang to study the result of a behavior modification program. The result has found that after the experiment group of family health leaders the average score of knowledge, the perception of Perceived benefit and the prevention behavior had increased over the previous experiments with statistically significant ( $p$-value $<0.05$ ). (Wisetsang et al., 2017).

Social support factors influenced the preventive behavior of helminthiasis among elderly in Sisaket Province. Counseling the elderly as a vulnerable group of the society needs to have better care because of health deterioration and chronic disease leading to lack of confidence in doing activities. Therefore, to be supported in healthcare, mental health, materials, and equipment needed to sustain life are very essential to get support from society so that the elderly have the potential to perform activities that promote their health. Social gathering is a helpful approach that promotes self-worth that can make the elderly more energetic and healthier and retards the dependency period. The concept was 
consistent with the previous study of Thongnamuang and Duangsong, the effectiveness of the health education program was studied by applying the theory of health education patterns. Belief in health together with social support for behavior modification to prevent liver fluke and cholangiocarcinoma among primary school students, After the experiment, the experimental group had knowledge of the risk perception, perception of severity ,perception of benefit and recognize barrier to preventing and behavioral practice to prevent liver fluke and cholangiocarcinoma were statistically significantly higher than before the trial and then the comparison group $(\mathrm{P}<0.001)$ (Thongnamuang and Duangsong, 2012).

The efficacy factor has influenced the preventive behavior of helminthiasis among the elderly in Sisaket Province. It affected the actions of 2 people who may not have different abilities but may be expressed in different qualities. If it found that these two people had different self-efficacy thus, may vary in different situations and may behave differently as well. It is recommended that the next research should focus on the development of health behavior modification models for the prevention and control of among the elderly. All sectors should be involved in the development of the model to obtain a model for changing behavior, prevention, and controlling helminthiasis to be more effective. The same study by Phatthanarat (2012) studied the results. Promotion of behavior for prevention of liver fluke disease among people by applying the theory of self-efficacy. The results showed that individuals had average scores for awareness and intent before the experiment and more than the comparison group was statistically significant at the .05 level. In terms of consumption practice, it was found that the experimental group had a higher level of good practice than the comparison group at a statistically significant level of .05 . And the experimental group had satisfied with the program statistically significant at 0.05 (Patanarat, 2012).

\section{Conclusion}

The overall outcome already found the prevalence of helminthiasis was $13.65 \%$ including hookworm, Taenia sp and Opisthorchis viverrini. The influencing factors were knowledge factors, perceived benefits factors, social support factors and self-efficacy factors. Therefore, intensive promoting and appropriate specific behavior will be decreased by helminthiasis. Thus, health care organizations should encourage the knowledge of self-care for the elderly by using effective implementation and specific investigations that will give the elderly confidence in doing activities.

Moreover, organizations in the community should focus on health care in elderly, closer care, encourage the elderly to take care and promote selfcare activities as well as modify and express health behaviors and encourage the elderly to play a role and participate in activities continuously. All of these can be effectively changing behavior and may include respecting, praising, and giving importance to create appropriate value as well as giving them opportunities to participate and do activities with the community and becoming a role model to persuade their children to do healthy activities in the community regularly.

\section{Acknowledgements}

The authors would like to thanks partial grants support from Faculty of Medicine, Mahasarakham University and Tropical and Parasitic Diseases Research Unit, Faculty of Medicine. Special Thanks for staffs from Sisaket Public Health Office and Silalad Public Health Office and community for data collection and research collaboration.

\section{References}

Ahmadiara, E. and Hajimohammadi, B., 2017, Editorial Parasitic Infections in Nursing Homes: A Permanent Threat for Elderly Health. Elderly Health Journal, Vol. 3(2), 55-56.

Bikash, S., Shiba, K. R., Singh, A. and Shrestha, A., 2006, Intertinal Parasitosis aming the Elderly People in Kathmandu Valley. Nepal Med. Coll. J., Vol. 8(4), 243-247.

CDC, 2019, Preliminary. Incidence and Trends of Infections with Pathogens Transmitted Commonly through Food - Foodborne Diseases Active Surveillance Network, 10 U.S. Sites, 2016-2019., Derontol. Rio. De. Janeiro, 20(2), 244-253.

Division of Health Promotion, Department of Health, Ministry of Public Health, 2012, Annual Report.119 pages. http://hp.anamai.moph.go.t$\mathrm{h} / \mathrm{main}$.php?filename=index_th.

Duangsong, R., Sota, C., Sittithaworn, P., Sarakarn, P. and Sriamporn, S., 2007, Health Behavior Development for Prevention of Liver Fluke Disease in Phu Wiang District, Khon Kaen Province. Khon Kaen University, 1-154.

Kasl, E. L., Font, W. F. and Criscione, C. D., 2018, Resolving Evolutionary Changes in Parasite Life Cycle Complexity: Molecular Phylogeny of the Trematode Genus Alloglossidium Indicates more than One Origin of Precociousness. Mol. Phylogenet. Evol., Vol. 126, 371-381. 
Kelly, K. and Maxwell, S. E., 2003, Sample Size for Multiple Regression: Obtaining Regression Coefficients that are Accurate, not Simply Significant. Psychological Methods, Vol. 8, 305-321.

Lin, C. X., Xie, H. G., Zhang, R. Y., Jiang, D. W. and Xie, X. L., 2015, Epidemiological Survey of Soil-Transmitted Helminth Infections in Fujian Province in 2015. Chinese Journal of Parasitology and Parasitic Diseases, Vol. 36(6), 611-615.

National Statistical Office, 2014, http://service.nso.go.th/nso/nsopublish/pubs/ebook/esyb57/files/assets/basichtml/index.html\#1 9.

Patanarat, P., 2012, The Effect of Promoting Consumption Behavior for Prevention of Liver Fluke Disease of People in Yang Talat District, Kalasin Province. Master of Public Health Thesis. Burapha University.

Phuttharak, P. and Siriphaporn, K., 2014, The Prevalence of Helminths and Protozoan Infections among Patients Attending at Thammasat University Hospital during the Year 2011 to 2013. Journal of Science and Technology, Vol. 22(6), 861-870.

Office of Policy and Strategy, Office of the Permanent Secretary, Ministry of Public Health, 2017, Online. Accessed From https://bps.ops.moph.go.th/index.php?mod=profi le $\&$ doc $=3$.

Saengprachat, A., 2010, Factors Associated with Prevention Behavior of Liver Cancer and Cholangiocarcinoma of People of Ubon Ratchathani Province. Master of Public Health Thesis Health Promotion Program Ubon Ratchathani Rajabhat University.

Santos, P. H. S., Barros, R. C. S., Gomes, K. V. G., Nery, A. A. and Casotti, C. A., 2017, Prevalence of Intestinal Parasitosis and Associated Factors among the Elderly. Rev. Bras. Geriatr. Derontol. Rio. De. Janeiro, Vol. 20(2), 244-253.

Silalad District Public Health Office Annual Report, 2016, Elderly Fair. Sisaket: Silat District Public Health Office Sisaket Province, 2016.

Suntaravitun, P. and Dokmaikaw, A., 2018, Prevalence of Intestinal Parasites and Associated Risk Factors for Infection among Rural Communities of Chachoengsao Province, Thailand. Korean J Parasitol., Vol. 56(1), 3339. doi: $10.3347 / \mathrm{kjp} .2018 .56 .1 .33$.
Thongnamuang, S. and Duangsong, R., 2012, Effectiveness of Health Education Program by Applying Health Belief Model Theory Together with Social Support for Behavior Modification in Liver Fluke and Cholangiocarcinoma Prevention. In Primary School Students, Moeiwadi District, Roi Et province. $K K U$ Research Journal, Vol. 12(2).

Ukkhati, A., Dhammasaccakarn, W. and Prom-in, S., 2008, Factors Affecting Health Behavior According to the National Health Recommendations among Village-HealthVolunteers in Satun Province. Songkhla Medical Journal, Vol. 26 (6), 527-538.

Sirikampeng, U. and Phosing, P., 2017, Long-term Care for the Dependent Elderly in the National Era. Thailand 4.0. Dhammathas Academic Journal, Vol. 17 (3), 235-243.

Wisetsang, W., Chatchanayuenyong, R. and Nithikathkul, C., 2017, Behavior Modification Program by Family Health Leader to Reducethe Occurrence of Liver Fluke among Working Age Group at Khayung Sub-district, Uthumphon Phisai District, Sisaket Province. Journal of the office DPC7 Khon Kean. Vol. 24(3), 61-74.

Wongsaroj, T., 2014, Community Survey Project to Study the Situation of Helminthic Infection in Thai People 76 Provinces of Thailand and Determinants of Diseases, 2014. Division of General of Communicable Diseases, Department of Diseases Control, Ministry of Public Health. 1-120.

Wongsaroj,T., Nithikathkul, C., Rojkitikul., Nakai, W., Royal, L. and Rammasut, P., 2014, National Survey Of Helminthiasis in Thailand. Asian Biomedicine, Vol. 8(6), 779-783.

World Health Organization, 2017, Guideline: Preventive Chemotherapy to Control Soil Transmitted Helminthes Infection in at Risk Population.World Health Organization, Geneva. $1-15$.

Zeng, X. I., Jiang, W.S., Xie, S. Y., Chen, Y. D., Gu, X. N., Ge, J., Hang, C. Q., Li, Z. J. and Chen, H. G., 2019, Effect of Integrated Control Intervention on Soil-Transmitted Helminth Infections in Jiangxi Province in Southeast China.Acta Tropica,Vol.194, 148-154. 